\title{
PARÂMETROS FISIOLÓGICOS, PRODUÇÃO DE AQUÊNIOS E FITOMASSA DE GIRASSOL EM DIFERENTES ÉPOCAS DE CULTIVO ${ }^{(1)}$
}

\author{
MARIA REGINA G. UNGARO ${ }^{(2,4)}$; SANDRA S. SEVÁ NOGUEIRA ${ }^{(2)}$; \\ VIOLETA NAGAI ${ }^{(3)}$
}

\begin{abstract}
RESUMO
O conhecimento das possíveis alterações no comportamento de cultivares de girassol, semeados em diferentes épocas, é essencial para a escolha do momento mais adequado para a semeadura. $\mathrm{O}$ objetivo do presente trabalho foi determinar o efeito da época de cultivo sobre alguns caracteres morfológicos e fisiológicos e sobre o rendimento de três cultivares de girassol semeados em doze épocas distintas. O experimento foi conduzido em Latossolo Vermelho, na Estação Experimental de Monte Alegre do Sul (SP), pertencente ao Instituto Agronômico. Utilizaram-se as populações IAC-Anhandy e VNIIMK e o híbrido Contisol 621 no delineamento com parcelas subdivididas, incluindo época de semeadura nas parcelas e cultivares na subparcela, com quatro repetições. As semeaduras foram realizadas, mensalmente, entre janeiro e dezembro de 1989. As amostragens foram feitas na fase R5.5, correspondente a $50 \%$ de florescimento para o índice de área foliar (IAF), e na maturação fisiológica (R5.9) para os demais parâmetros. Houve interação significativa entre época e cultivar para todos os caracteres avaliados, destacando-se a importância de se conhecer a resposta do cultivar a diferentes ambientes. Em termos de rendimento de grãos e fitomassa, IAC-Anhandy apresentou melhores resultados na semeadura de janeiro, enquanto VNIIMK foi melhor em agosto e Contisol 621, em junho. O híbrido Contisol 621 apresentou produção de fitomassa inferior e um índice de colheita ligeiramente superior às duas populações analisadas.
\end{abstract}

Palavras-chave: Helianthus annuиs L., cultivar, massa seca, índice de área foliar, índice de colheita.

\section{ABSTRACT \\ PHYSIOLOGICAL PARAMETERS, GRAIN AND DRY MATTER YIELD OF SUNFLOWER CULTIVATED IN DIFFERENT SOWING DATES}

The knowledge of possible changes in sunflower cultivars due to different sowing dates is very important for sunflower cultivation. The objective of this research was to determine the effect of sowing date on some physiological characteristics, dry matter and grain yield of three sunflower cultivars sowed in twelve consecutive sowing dates ranging from January to December, 1989. The study was carried out in a field experiment, in the IAC Experimental Station of Monte Alegre do Sul (Latitude: $22^{\circ} 41^{\prime}$ S; Longitude: $46^{\circ} 43^{\prime} \mathrm{W}$; Altitude: $777 \mathrm{~m}$ ), Brazil. The genotypes used were the varieties IAC-Anhandy and VNIIMK 8931, and the hybrid Contisol 621, in a split-plot design with sowing dates and cultivars, with four replications. The evaluations were done at phenostage R5.5, corresponding to $50 \%$ of flowering for leaf area index (LAI) and at physiological maturity (R5.9) for the remaining data. There was a significant interaction between sowing date and cultivar for all the studied characteristics,

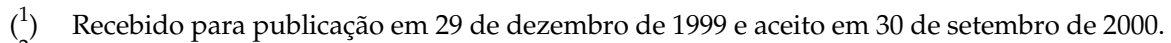

$\left({ }^{2}\right)$ Centro de Plantas Graníferas, Instituto Agronômico, Caixa Postal 28, 13001-970 Campinas (SP). Brasil. E-mail: ungaro@cec.iac.br

(3) Laboratório de Análise e Metodologia Quantitativa, IAC.

$\left({ }^{4}\right)$ Com bolsa de produtividade em pesquisa do CNPq. 
pointing out the importance of the knowledge of cultivar response to different behaviour. The highest total dry matter(TDM) and grain yield(GDM) were observed in the sowing date of January for IAC-Anhandy; June for Contisol 621, and in July for dry matter and August for grain yield in the case of VNIIMK. Contisol 621 presented less dry matter yield but with a better efficiency due to a slightly higher harvest index in comparison with the two populations.

Key words: Helianthus annuus L., cultivar, dry matter, leaf area index, harvest index.

\section{INTRODUÇÃO}

O girassol é uma planta extremamente adaptável a diferentes condições ambientais (CARTER, 1978). A época de plantio normalmente influencia a produção de grãos e seus componentes. Dependendo da região do País essa planta pode ser indicada para semeadura na "safrinha" (fevereiro-março), verão, outono. RAMOS (1995) encontrou, para as condições de Goiás, boas produções de aquênios nas semeaduras de outubro e de fevereiro, porém muito baixas nas de março, enquanto Daros e Ronzelli (1993) e Rizzardi e Milgiorança (1993), respectivamente, no Paraná e no Rio Grande do Sul, verificaram variações significativas no rendimento de aquênios em semeaduras realizadas entre setembro e novembro, sendo as maiores produções obtidas na semeadura de setembro. No Rio Grande do Sul a época de semeadura causou, também, alteração na área foliar das plantas (SANGOI e SILVA, 1985), ao passo que no planalto catarinense, SANGOI e KRUSE (1993) encontraram interação significativa entre cultivar e época de semeadura para produção de aquênios e seus componentes.

Na Argentina a época de semeadura teve influência no ciclo e na altura de planta, no diâmetro de capítulo, na produção de aquênios, eficiência da planta e área foliar (CHOLAKY et al., 1985).

BANGE et. al. (1996), estudando o comportamento do girassol em algumas épocas de semeadura, verificaram que o índice de área foliar (IAF) na antese variou entre 2,4 e 7,2 e foi dependente da aplicação de $\mathrm{N}$ e da época de semeadura. Em geral, alto IAF esteve associado à intensa acumulação de biomassa e produção de grãos; no entanto, condições de baixos níveis de radiação e temperatura do ar durante o enchimento de grãos resultaram em menor quantidade de fitomassa total, apesar do alto IAF.

Um IAF entre 2,5 e 3,0, obtido durante o florescimento, é suficiente para assegurar boa produtividade; entretanto, é essencial manter a atividade fotossintética dessa superfície foliar após o florescimento, uma vez que o enchimento de grãos caracteriza-se por ser um período de forte competição entre os assimilados, podendo ocorrer abortamento de aquênios nas plantas que apresentam superfície foliar incipiente, sobretudo como decorrência de senescência precoce (MerRIEN e MiLAN, 1992).
Uma vez que UnGARO et al. (1992 e 1997) já haviam encontrado comportamento diferenciado dependente da época de semeadura, dos mesmos cultivares (avaliados neste trabalho), com respeito aos aspectos de temperatura ótima para a produção de óleo nos aquênios e nível da dormência das sementes logo após a colheita, a presente pesquisa enfocou a avaliação do comportamento dos mesmos genótipos quanto à produção de aquênios e de fitomassa, submetidos a épocas distintas de semeadura.

\section{MATERIAL E MÉTODOS}

O estudo foi realizado na Estação Experimental do IAC, em Monte Alegre do Sul (SP), localizada a $22^{\circ} 41^{\prime} \mathrm{S}$ de latitude, $46^{\circ} 43^{\prime} \mathrm{W}$ de longitude e $777 \mathrm{~m}$ de altitude. O ensaio foi conduzido em Latossolo Vermelho, no delineamento com parcelas subdivididas contendo época de semeadura nas parcelas e cultivares na subparcela. Foram utilizadas quatro repetições.

Cada subparcela foi constituída por cinco linhas de $5 \mathrm{~m}$ de comprimento, espaçadas de 1,0 $\mathrm{m}$. Foram utilizadas as variedades de polinização aberta IACAnhandy e VNIIMK e o híbrido Contisol 621. A semeadura foi feita manualmente, colocando-se de três a quatro sementes a cada $0,20 \mathrm{~cm}$. Cerca de dez dias após a emergência procedeu-se ao desbaste para ajuste da população de plantas, deixando-se cinco plantas por metro. No intervalo de 30 a 40 dias após a emergência foi aplicado, em cobertura, 40 kg.ha ${ }^{-1}$ de nitrogênio e 2 kg.ha ${ }^{-1}$ de boro.

Foram avaliados, entre janeiro e dezembro de 1989, os dados de 12 semeaduras distintas: nas de julho e agosto foi realizada uma irrigação por aspersão logo após a semeadura, para garantir uma emergência uniforme; as semeaduras de maio e junho receberam uma irrigação aos 15 dias após a emergência; a de outubro recebeu várias irrigações suplementares, e seus resultados foram retirados da análise estatística e apresentados apenas para efeito ilustrativo. As demais não receberam irrigação suplementar.

Foram coletados dados de massa da matéria seca de haste, folha, capítulo e grão, e altura de planta na maturação fisiológica, enquanto a área foliar foi medida no estádio R5.5 (SCHNEITER e MilLeR, 1981), corres- 
pondente a $50 \%$ de florescimento; com os dados de área foliar foi obtido o IAF.

As avaliações foram feitas coletando-se cinco plantas competitivas da área útil da subparcela, as quais foram separadas em haste, folhas + pecíolo e capítulo. As partes da planta foram postas a secar em estufa a $60^{\circ} \mathrm{C}$ até atingir massa constante, quando então foram pesadas e separados os grãos para avaliação de produção.

Seguindo método descrito por Eze (1973), a área foliar foi avaliada a partir da retirada de círculos de área conhecida, extraídos de cinco plantas colhidas na fase R5.5. Esses círculos foram contados, secos na estufa, e utilizados para o cálculo da massa seca. A área foliar foi obtida através da relação entre a massa dos círculos, sua área e a massa total das folhas.

Os parâmetros avaliados foram submetidos à análise de variância; a comparação de médias foi feita pelo teste de Tukey a $5 \%$.

\section{RESULTADOS E DISCUSSÃO}

O ano agrícola 89/90 caracterizou-se por uma certa anormalidade com respeito à distribuição de chuvas. A figura 1 mostra a pouca precipitação ocorrida em outubro, mês tradicionalmente chuvoso, e uma quantidade de água, em julho, acima do esperado. Houve diferença, entre as épocas, no tocante à disponibilidade de água e distribuição das chuvas. Assim, as épocas de semeadura entre novembro e janeiro não passaram por restrição hídrica, como já era esperado, uma vez que são épocas de altos índices pluviométricos no Estado de São Paulo. No entanto, outubro foi excepcionalmente seco, com um total de $11 \mathrm{~mm}$ de chuva, fato que contribuiu substancial- mente para a baixa produção encontrada nessa semeadura, bem como na de novembro, bastante anormal em relação ao esperado. A semeadura de setembro provavelmente foi também afetada pela estiagem de outubro.

Uma vez que se procedeu à irrigação durante todo o mês de outubro, somada a chuvas abundantes em novembro, tanto as semeaduras de outubro como as de novembro foram bastante afetadas pela alternariose, uma das principais doenças fúngicas do girassol, conforme discutido no trabalho de DudIENAs et al. (1998), cujas avaliações de doença foram realizadas no referido experimento. Um dos fatores que certamente contribuiu para as boas produções obtidas nas semeaduras de julho e agosto foi a menor incidência de Alternaria, conforme relatado por SANGOI e KRUSE (1993) e por SENTELHAS et al. (1996).

A análise de variância (Quadro 1) detectou diferenças altamente significativas entre as épocas de semeadura, os cultivares e a interação época x culti-

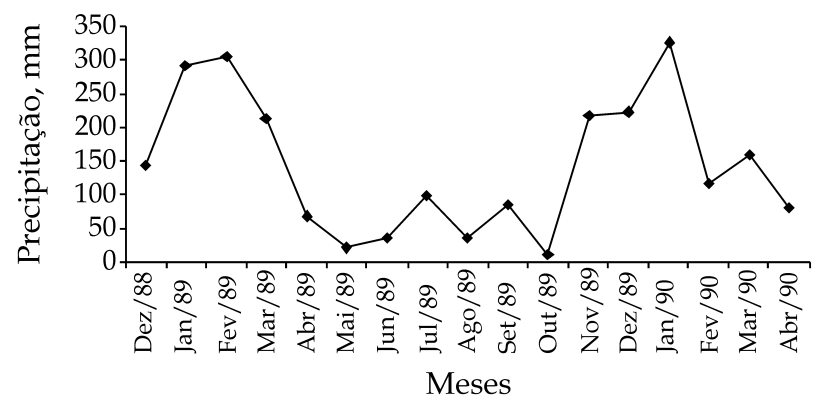

Figura 1. Distribuição mensal de chuva em mm ocorrida em Monte Alegre do Sul, no período de condução do ensaio.

Quadro 1. Análise de variância conjunta dos dados de altura de planta, de matéria seca de folha (MSF), de haste (MSH), de capítulo (MSC), de aquênio (PROD) e índice de área foliar (IAF) em diferentes épocas de semeadura, para três cultivares de girassol

\begin{tabular}{|c|c|c|c|c|c|c|c|}
\hline \multirow[t]{2}{*}{ Causas de Variação } & \multirow[b]{2}{*}{ G.L. } & \multicolumn{6}{|c|}{ Teste F } \\
\hline & & $\mathrm{AP}$ & MSF & $\mathrm{MSH}$ & MSC & PROD & IAF \\
\hline Época & 10 & $113,24^{* *}$ & $21,75^{* *}$ & $27,58^{* *}$ & $39,85^{* *}$ & $71,65^{* *}$ & $8,36^{* *}$ \\
\hline Bloco & 3 & $0,64^{\mathrm{ns}}$ & $0,91^{\mathrm{ns}}$ & $0,54^{\mathrm{ns}}$ & $3,71^{*}$ & $0,17^{\mathrm{ns}}$ & $1,18^{\mathrm{ns}}$ \\
\hline Resíduo(A) & 30 & & & & & & \\
\hline Cultivar & 2 & $2164,48^{* *}$ & $186,51^{* *}$ & $253,00^{* *}$ & $1,14^{\text {n.s }}$. & $11,74^{* *}$ & $31,48^{* *}$ \\
\hline Época x Cultivar & 20 & $9,69^{* *}$ & $6,89^{* *}$ & $12,01^{* *}$ & $20,74^{* *}$ & $18,30^{* *}$ & $5,72^{* *}$ \\
\hline Resíduo(B) & 6 & & & & & & \\
\hline Resíduo $\left(A^{*} B^{*} C\right)$ & 60 & & & & & & \\
\hline Total & 131 & & & & & & \\
\hline $\mathrm{CV} \%$ & & 4,58 & 9,00 & 9,78 & 10,48 & 13,79 & 10,75 \\
\hline Média & & 171,51 & 99,05 & 285,12 & 153,36 & 102,84 & 2,90 \\
\hline
\end{tabular}

*Significativo a $5 \%$ de probabilidade. ** Significativo a $1 \%$ de probabilidade. ${ }^{\text {ns }}$ Não significativo. 
var, para as características morfológicas e de produtividade do girassol. A massa da matéria seca de capítulo foi exceção, dado que, para a mesma não foi encontrada diferença estatisticamente significativa entre os cultivares.

De maneira geral IAC-Anhandy e VNIIMK apresentaram altura de planta bastante próxima, com interação época $x$ cultivar facilmente visualizada na figura 2; o cultivar Contisol 621 apresentou porte menor em todas as épocas de semeadura, sendo estatisticamente não-diferente dos demais na semeadura de junho.

O quadro 2 mostra diferença bastante acentuada entre as produções de fitomassa de folha em distintas épocas de semeadura. A variação total encontrada ficou entre 54,3 g/5 plantas para Contisol 621 e 146,2 $\mathrm{g} / 5$ plantas para IAC-Anhandy. As maiores produções foram obtidas em maio, janeiro e julho para IAC-Anhandy, fevereiro e julho para VNIIMK, junho e julho para Contisol 621.

A massa da matéria seca de haste (Quadro 3) diferiu bastante entre os cultivares e as épocas. As semeaduras de janeiro e dezembro beneficiaram as variedades, enquanto a de junho foi mais propícia para o híbrido. $\mathrm{O}$ maior valor foi encontrado para IAC-Anhandy na semeadura de setembro, com $402 \mathrm{~g} / 5$ plantas, enquanto o menor ficou com o híbrido, na semeadura de março, com 138,7 g/5 plantas.

Ocorreu interação significativa entre época e cultivar para o parâmetro massa da matéria seca de capítulo. $\mathrm{O}$ quadro 4 mostra que, na semeadura de janeiro, o cv IAC-Anhandy foi superior a VNIIMK e eqüivalente a Contisol 621; em fevereiro, VNIIMK superou os demais, sendo a pior produção obtida por Contisol 621. Em abril, Contisol 621 produziu cerca de 800 kg.ha- ${ }^{-1}$ a mais que os outros dois.

O quadro 5 apresenta as diferenças na produção de aquênios entre as épocas de semeadura. A amplitude de variação para as produções obtidas entre a época mais favorável, em comparação com a menos favorável, na região avaliada, foi de cerca de 2.000 kg.ha ${ }^{-1}$ (200 g/5 plantas). Essa diferença encontrada é compatível com os resultados obtidos por BEVITORI e BALLA (1995), que relatam, em Goiás, aumentos de até 1.749 kg.ha ${ }^{-1}$ no rendimento de aquênios, somente com a mudança da época de semeadura; da mesma forma, RIZZARDI e MILGIORANÇA (1993) verificaram uma diferença de $2.023 \mathrm{~kg} \cdot \mathrm{ha}^{-1}$ entre as semeaduras de janeiro e de julho.

Uma comparação entre as médias gerais de produção de grãos, no quadro 5 , mostra a variedade IAC-Anhandy como a mais produtiva, seguida por VNIIMK e, em patamar inferior às demais, o híbrido Contisol 621. Na maioria das épocas avaliadas a pro- dução de aquênios ficou aquém da produção alcançada em outras condições edafo-climáticas, como as obtidas por SANGOI e SILVA (1985) e por SANGOI e KRUSE (1993). No entanto, vale ressaltar que as épocas de janeiro e julho resultaram em produções de aquênio ao redor de $2.000 \mathrm{~kg} \cdot \mathrm{ha}^{-1}$, valor compatível com os dados da literatura e com o potencial dos genótipos em estudo.

Também em Monte Alegre do Sul, com os mesmos cultivares, foi verificado que a temperatura do ar teve relação inversa com a duração do ciclo da cultura (SeNTELHAS et. al., 1994). IAC-Anhandy e Contisol 621

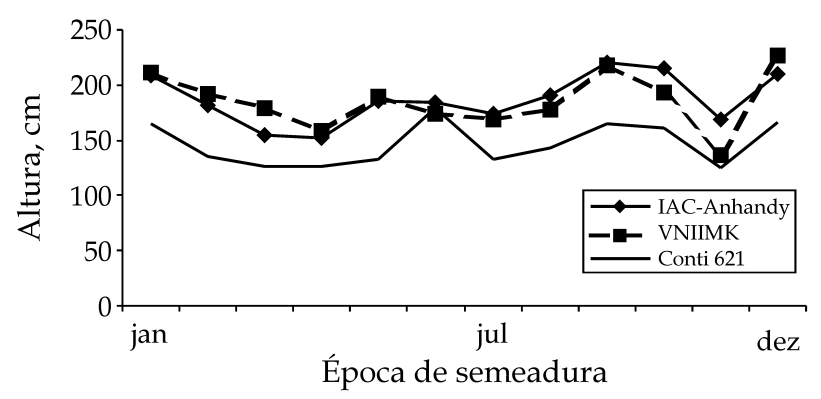

Figura 2. Altura de planta para três cultivares em diferentes épocas de semeadura, 1989.

Quadro 2. Matéria seca de folha para três cultivares de girassol em diferentes épocas de semeadura (média de quatro repetições). Resultados em g/5 plantas

\begin{tabular}{lccc}
\hline & \multicolumn{3}{c}{ Massa Seca de Folha } \\
\cline { 2 - 4 } Época * & IAC-Anhandy ** & VNIIMK & $\begin{array}{c}\text { Contisol } \\
621\end{array}$ \\
\hline Janeiro & $123,5 \mathrm{ab} \mathrm{A}$ & 95,5 de B & 77,7 de C \\
Fevereiro & 97,5 de B & 146,2 a A & 76,9 de C \\
Março & 69,5 f B & 79,2 f A & 54,3 f C \\
Abril & 102,5 cd B & 111,0 bcd A & 97,5 abc B \\
Maio & 125,0 a A & 124,7 b A & 88,7 bcd B \\
Junho & 101,7 cd B & 125,7 b A & 106,0 a B \\
Julho & 117,5 abc B & 143,5 a A & 100,0 ab C \\
Agosto & 109,0 bcd A & 113,5 bc A & 74,5 de B \\
Setembro & 99,0 de B & 114,0 bc A & 83,0 cde C \\
Outubro & 85,0 & 100,2 & 83,7 \\
Novembro & 85,7 e A & 86,2 ef A & 69,0 ef B \\
Dezembro & 93,2 de B & 106,2 cd A & 70,7 e C \\
\hline Média & 102,2 B & 113,3 A & 81,7 C \\
\hline
\end{tabular}

*Médias seguidas por uma mesma letra minúscula em cada coluna não diferem estatisticamente pelo teste Tukey a $5 \%$.

**Médias seguidas por mesmas letras maiúsculas na linha indicam a não-existência de diferenças entre os cultivares em uma mesma época de semeadura. 
Quadro 3. Matéria seca de haste para três cultivares de girassol em diferentes épocas de semeadura (média de quatro repetições). Resultados em $\mathrm{g} / 5$ plantas.

\begin{tabular}{lrrr}
\hline \multirow{2}{*}{ Época* } & \multicolumn{3}{c}{ Massa Seca de Haste } \\
\cline { 2 - 4 } & IAC-Anhandy** & VNIIMK & Contisol 621 \\
\hline Janeiro & 397,5 a A & 382,7 ab A & 200,7 cd B \\
Fevereiro & 265,7 d B & 332,2 cdef A & 174,5 de C \\
Março & 300,2 bcd A & 297,2 f A & 138,7 e B \\
Abril & 271,7 cd B & 352,5 bcd A & 250,7 b C \\
Maio & 385,7 a A & 366,2 abc B & 228,7 bc C \\
Junho & 263,2 de C & 303,5 ef B & 329,5 a A \\
Julho & 336,0 b A & 344,7 bcde A & 227,0 bc B \\
Agosto & 310,5 bc A & 248,2 g B & 182,2 d C \\
Setembro & 402,0 a A & 320,5 def B & 250,7 b C \\
Outubro & 324,2 & 259,0 & 196,7 \\
Novembro & 221,0 e A & 173,7 h B & 164,7 de B \\
Dezembro & 380,7 a B & 401,5 a A & 201,5 cd C \\
\hline Média & 321,3 A & 320,3 A & 213,7 B \\
\hline
\end{tabular}

*Médias seguidas por uma mesma letra minúscula em cada coluna não diferem estatisticamente pelo teste Tukey a 5\%.

**Médias seguidas por mesmas letras maiúsculas na linha indicam a não-existência de diferenças entre os cultivares em uma mesma época de semeadura.

apresentaram ciclo semelhante, ao passo que VNIIMK foi mais tardio. Em geral cultivares mais tardios tendem a ser mais produtivos porque têm mais tempo para fotossintetizar; no entanto, outros fatores, como grau de sensibilidade a doenças e área foliar, podem interferir nessa relação. DuDIENAS et al. (1998) encontraram maior incidência de alternariose no cv VNIIMK, quando comparado a Contisol 621. Apesar disso, o híbrido mostrou menor capacidade produtiva, o que reforça a idéia da duração do ciclo como fator importante na produtividade.

Os cultivares apresentaram ótima produção de massa de matéria seca total (Figura 3), com o pior desempenho em torno de 4.000 kg.ha ${ }^{-1}$, obtidos com o híbrido Contisol 621, o qual também já havia demonstrado menor capacidade produtiva para aquênios e menor estatura de planta. Os melhores resultados de produção de aquênios e de massa de matéria seca foram obtidos por VNIIMK, o mais tardio dos três, ficando IAC-Anhandy em situação intermediária aos demais.

Na semeadura de abril, mesmo com os altos valores obtidos para a maioria dos parâmetros fisiológicos, a produção de grãos (Quadro 5) foi inferior à esperada, provavelmente como conseqüência direta da colheita antecipada (anterior à maturação fisi-
Quadro 4. Matéria seca de capítulo para três cultivares de girassol em diferentes épocas de semeadura (média de quatro repetições). Resultados em g/5 plantas.

\begin{tabular}{lrrr}
\hline \multirow{2}{*}{ Época* } & \multicolumn{3}{c}{ Matéria Seca de Capítulo } \\
\cline { 2 - 4 } & IAC-Anhandy** & VNIIMK & Contisol 621 \\
\hline Janeiro & $219,7 \mathrm{ab}$ A & 159,7 de C & 206,0 a B \\
Fevereiro & 145,5 de B & 169,7 cd A & 95,5 fg C \\
Março & 171,0 cd A & 146,7 de B & 115,2 ef C \\
Abril & 103,7 gh B & 98,7 gh B & 181,7 abc A \\
Maio & 194,7 bc A & 197,2 bc A & 187,2 ab A \\
Junho & 143,5 de C & 162,7 de B & 186,2 ab A \\
Julho & 245,0 a A & 199,0 b B & 158,0 cd C \\
Agosto & 164,2 d B & 239,0 a A & 138,0 de C \\
Setembro & 108,5 fg C & 136,7 ef B & 159,5 bcd A \\
Outubro & 67,2 & 98,0 & 88,2 \\
Novembro & 79,2 h B & 71,5 h B & 144,0 d A \\
Dezembro & 133,7 ef A & 118,2 fg B & 80,7 g C \\
\hline Média & 155,4 A & 154,5 A & 150,2 A \\
\hline
\end{tabular}

*Médias seguidas por uma mesma letra minúscula em cada coluna não diferem estatisticamente pelo teste Tukey a $5 \%$.

**Médias seguidas por mesmas letras maiúsculas na linha indicam a não-existência de diferenças entre os cultivares em uma mesma época de semeadura.

Quadro 5. Matéria seca de aquênio para três cultivares de girassol em diferentes épocas de semeadura (média de quatro repetições). Resultados em g/5 plantas.

\begin{tabular}{lrrr}
\hline \multirow{2}{*}{ Época* } & \multicolumn{3}{c}{ Matéria Seca de Aquênio } \\
\cline { 2 - 4 } & IAC-Anhandy** & VNIIMK & Contisol 621 \\
\hline Janeiro & 192,2 a A & 141,5 ab C & 181,0 a B \\
Fevereiro & 81,7 de A & 92,5 d A & 66,7 ef B \\
Março & 71,1 e A & 67,7 e A & 28,5 g B \\
Abril & 47,7 f B & 48,7 ef B & 80,0 cdef A \\
Maio & 97,2 d A & 103,0 cd A & 95,2 cd A \\
Junho & 121,0 c C & 138,0 b B & 157,0 b A \\
Julho & 175,7 a A & 154,2 ab B & 59,2 f C \\
Agosto & 133,2 bc B & 161,7 a A & 81,7 c de C \\
Setembro & 89,5 de B & 115,7 c A & 99,0 c B \\
Outubro & 34,2 & 49,0 & 39,5 \\
Novembro & 46,7 f B & 35,7 f B & 97,2 cd A \\
Dezembro & 145,0 b A & 111,5 cd B & 76,2 de f C \\
\hline Média & 109,2 A & 106,4 A & 92,9 B \\
\hline
\end{tabular}

*Médias seguidas por uma mesma letra minúscula em cada coluna não diferem estatisticamente pelo teste Tukey a $5 \%$ ** Médias seguidas por mesmas letras maiúsculas na linha indicam a não-existência de diferenças entre os cultivares em uma mesma época de semeadura. 


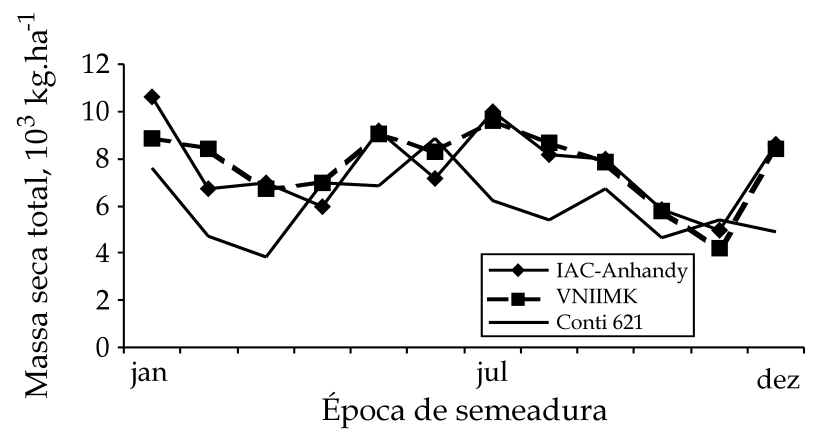

Figura 3. Matéria seca total para três cultivares de girassol em diferentes épocas de semeadura. Mëdia de quatro repetições.

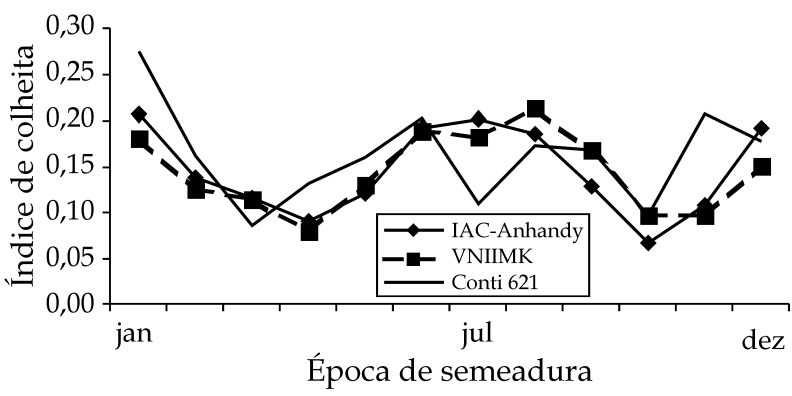

Figura 4. Índice de colheita para três cultivares de girassol em diferentes épocas de semeadura, no ano de 1989. Média de quatro repetições.

ológica) necessária, devido à forte chuva que causou tombamento generalizado das plantas. O efeito da não-finalização do enchimento de grãos pode ser detectado pelo baixo índice de colheita (relação MSGrão/MSTO) apresentada especialmente pelas duas variedades mais tardias, nessa época (Figura 4).

Para produção de fitomassa IAC-Anhandy foi, na média, inferior à VNIIMK. No entanto, na semeadura de janeiro ela produziu um total de fitomassa seca superior ao VNIIMK em mais de $100 \mathrm{~kg} \cdot \mathrm{ha}^{-1}$.

O maior IAF foi obtido para cv VNIIMK semeado em fevereiro, seguido pelo híbrido em junho e IACAnhandy em janeiro (Quadro 6).

A análise de correlação (Quadro 7) entre os parâmetros mostrou a produção de fitomassa total como intrinsecamente correlacionada à produção de grãos, ao IAF, à massa de matéria seca de capítulo e à altura de planta. O IAF apresentou, também, alta correlação com a fitomassa de haste e com a altura de planta. A massa de matéria seca de haste mostrou correlação altamente significativa com massa de matéria seca de folha e altura de planta. Resultados semelhantes foram obtidos por Calvet e Ungaro (2000) que, avaliando seis genótipos de girassol, en-
Quadro 6. Índice de área foliar para três cultivares de girassol em diferentes épocas de semeadura (média de quatro repetições)

\begin{tabular}{lccc}
\hline \multirow{2}{*}{ Época* } & \multicolumn{3}{c}{ Índice de Área Foliar } \\
\cline { 2 - 4 } & IAC-Anhandy** & VNIIMK & Contisol 621 \\
\hline Janeiro & 3,58 a A & 2,88 c de B & 2,56 cd C \\
Fevereiro & 2,84 bc de B & 3,91 a A & 2,67 bcd B \\
Março & 2,47 de B & 2,77 de A & 1,83 e C \\
Abril & 3,07 abc B & 3,44 abc A & 3,23 ab B \\
Maio & 2,81 bc de B & 3,04 bcd A & 2,50 cd C \\
Junho & 2,98 bcd C & 3,48 ab B & 3,77 a A \\
Julho & 3,25 ab A & 3,30 bcd A & 2,95 bc B \\
Agosto & 3,34 ab A & 3,14 bcd A & 2,17 de B \\
Setembro & 2,52 cde B & 3,17 bcd A & 2,47 cd B \\
Outubro & 2,75 & 3,45 & 2,77 \\
Novembro & 2,38 e A & 2,39 e A & 2,35 de A \\
Dezembro & 2,94 bc de B & 3,25 bcd A & 2,31 cde C \\
\hline Média & 2,93 B & 3,16 A & 2,62 C \\
\hline
\end{tabular}

*Médias seguidas por uma mesma letra minúscula em cada coluna não diferem estatisticamente pelo teste Tukey a 5\%.

**Médias seguidas por mesmas letras maiúsculas na linha indicam a não-existência de diferenças entre os cultivares em uma mesma época de semeadura.

Quadro 7. Coeficientes de correlação $(\mathrm{p}<0,01)$ obtidos entre os parâmetros avaliados

\begin{tabular}{lccc}
\hline Correlação & IAC-Anhandy & VNIIMK & Contisol 621 \\
\hline IAF x AP & 0,74 & 0,79 & 0,82 \\
IAF x MSC & 0,34 & 0,55 & 0,58 \\
IAF x MSTO & 0,67 & 0,80 & 0,89 \\
IAF x MSH & 0,68 & 0,80 & 0,90 \\
IAF x PROD & 0,53 & 0,57 & 0,68 \\
MSTO x AP & 0,74 & 0,78 & 0,78 \\
MSTO x MSC & 0,81 & 0,82 & 0,83 \\
MSTO x PROD & 0,87 & 0,88 & 0,87 \\
MSC x AP & 0,30 & 0,51 & 0,39 \\
MSC x MSF & 0,55 & 0,71 & 0,58 \\
MSC x PROD & 0,82 & 0,82 & 0,79 \\
MSH x AP & 0,79 & 0,69 & 0,71 \\
MSH x MSF & 0,82 & 0,81 & 0,83 \\
MSH x MSC & 0,52 & 0,52 & 0,62 \\
PROD x AP & 0,51 & 0,60 & 0,65 \\
\hline
\end{tabular}

IAF = índice de área foliar. MSC = massa seca de capítulo. $\mathrm{AP}=$ altura de planta.

MSTO = massa seca total. MSH = massa seca de haste.

$\mathrm{MSF}=$ massa seca de folha. $\mathrm{PROD}=$ produção de aquênios. 
contraram correlações significativas entre altura de planta e produção de grãos, e entre IAF e massa de matéria seca total, altura de planta e produção de grãos.

As correlações envolvendo IAF e fitomassa tenderam a ser maiores no cultivar VNIIMK e no híbrido Contisol 621; as que envolvem produção de grãos foram semelhantes nos três genótipos. Os cultivares mostraram aptidão para produção de aquênios e fitomassa, principalmente nas semeaduras de janeiro para IAC-Anhandy (Quadro 5 e Figura 3), seguida pela de julho; para VNIIMK nas de julho e agosto, enquanto para Contisol 621 foram as semeaduras de janeiro e junho.

\section{CONCLUSÕES}

1. Houve interação significativa entre época e cultivar para todos os caracteres avaliados.

2. Em termos de rendimento de aquênios e fitomassa, IAC-Anhandy apresentou melhores resultados na semeadura de janeiro, VNIIMK em julho e agosto e Contisol 621 em janeiro e junho.

3. O cv. Contisol 621 mostrou produção de aquênios e de massa seca inferior aos outros dois, porém com índice de colheita ligeiramente superior.

4. Houve expressiva correlação positiva entre os parâmetros massa de matéria seca total, produção de aquênios, altura de planta, massa de matéria seca de capítulo e IAF.

\section{REFERÊNCIAS BIBLIOGRÁFICAS}

BANGE, M.; HAMMER, G.; RICKERT, K. Physiological determinants of potential yield of sunflower. In: INTERNATIONAL SUNFLOWER CONFERENCE, 14., 1996. Beijing/Shenyang. Proceedings... Beijing: Lyaoning Academy of Agricultural Sciences, 1996. v.1, p.570-575.

BEVITORI, R.; BALLA, A.J. Época de semeadura de girassol para o Estado de Goiás. In: REUNIÃO NACIONAL DE PESQUISA DE GIRASSOL, 11., 1995. Goiânia. Resumos... Londrina: Embrapa/IAC, 1995. p.21.

CALVET, N.P.; UNGARO, M.R.G. Correlation between physiological index, sunflower plant heigth and dry matter in different phenological stages. In: INTERNATIONAL SUNFLOWER CONFERENCE, 15., 2000. Toulouse. Proceedings.... Toulouse: International Sunflower Association, 2000. v.1, p.D117-D122.

CARTER, J. F. Sunflower Science and Technology. Madison:. The American Society of Agronomy, 1978.375p. (Agronomy monography, 19).

CHOLAKY, L.; GIAYETTO, O.; NEUMANN, E.C. 1985. Épocas de siembra: efectos sobre el desarrollo, morfología, componentes del rendimiento y producción de girasoles de ciclos diferenciados. In: INTERNATIONAL SUN-
FLOWER CONFERENCE, 10., 1985. Mar del Plata. Proceedings... Buenos Aires: ASAGIR, 1985.v.1, p.155-160.

DAROS, E.; RONZELLI JUNIOR, P. Resposta do girassol à época de semeadura, no primeiro planalto paranaense, safra 92/93. In: REUNIÃO NACIONAL DE PESQUISA DE GIRASSOL, 10., 1993. Goiânia. Resumos...Campinas: IAC/Embrapa, 1993. p.67

DUDIENAS, C.;UNGARO, M.R.G.;MORAES,S.A. Alternaria disease development under tropical conditions. Helia, Novi Sad, v.21, n.29, p.63-72. 1998.

EZE, J.M. The vegetative growth of Helianthus annuus and Phaseolus vulgaris as affected by seasonal factors in Freetown, Sierra Leone. Annals of Botany, Bristol, v.37, p.315329, 1973.

MERRIEN, A.; MILAN, M.J. Physiologie du Tournesol. Paris: CETIOM, 1992. 66p.

RAMOS, J.G. Efeito de seis épocas de plantio em três híbridos de girassol, em Senador Canedo, Estado de Goiás. In: REUNIÃO NACIONAL DE PESQUISA DE GIRASSOL, 11., 1995. Goiânia. Resumos... Goiânia:Embrapa/CNPAF; EMGOPA, 1995. p.23.

RIZZARDI,M.A.;MILGIORANÇA, M.E. Reação decultivares de girassol à época de semadura no planalto médio rio-grandense. In: REUNIÃO NACIONAL DE PESQUISA DE GIRASSOL, 10., 1993. Goiânia. Resumos... Campinas: IAC/Embrapa, 1993. p.55-56.

SANGOI, L.; KRUSE, N.D. Comportamento de cultivares de girassol em diferentes épocas de semeadura no planalto catarinense. Pesquisa Agropecuária Brasileira, Brasília, v.28, n.1, p.81-91, 1993.

SANGOI, L; SILVA, P.R.F. Época de semeadura em girassol. II.Efeitos no índice de área foliar, incidência de moléstias, rendimento biológico e índice de colheita. Lavoura Arrozeira, Porto Alegre, v.36, n.362, p.6-13, 1985.

SCHNEITER, A.A.; MILLER, J.F. Description of sunflower growth stages. Crop Science, Madison, v.21, p.901-903, 1981.

SENTELHAS, P.C.; NOGUEIRA, S.S.S.; PEDRO JÚNIOR, M.; SANTOS, R.R. Temperatura-base e graus-dia para cultivares de girassol. Revista Brasileira de Agrometeorologia, Santa Maria, v.2, n.1, p. 43-49, 1994.

SENTELHAS, P.C.; PEZZOPANE, J.R.M.; UNGARO, M.R.G.; MORAES, S.A.; DUDIENAS, C. Aspectos climáticos relacionados à ocorrência da mancha de Alternária em cultivares de girassol. Fitopatologia Brasileira, Brasília, v.21, n.4, p.464-469. 1996.

UNGARO, M.R.G.; MAEDA, J.A.; SANTOS, R.R. Relation between planting and harvest dates and sunflower "seed" dormancy. INTERNATIONAL SUNFLOWER CONFERENCE, 13., Pisa, 1992. Proceedings... Pisa: International Sunflower Association, 1992, v.1, p.447-452.

UNGARO, M.R.G.; SENTELHAS, P.C.; TURATTI, J.M.; SOAVE, D. Influência da temperatura do ar na composição de aquênios de girassol. Pesquisa Agropecuária Brasileira, Brasília, v.32, n.4, p.351-356, 1997. 